\title{
Determinants of suboptimal immune recovery among a Chinese Yi ethnicity population with sustained HIV suppression
}

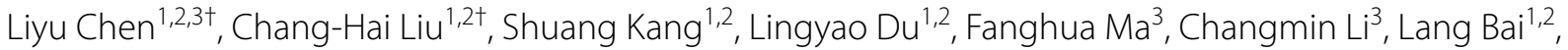
Hong Li $i^{1,2^{*}}$ and Hong Tang ${ }^{1,2^{*}}$

\begin{abstract}
Objectives: Despite sustained viral suppression with effective antiretroviral therapy (ART), HIV-infected patients with suboptimal immune recovery are still at high risk of both non-AIDS-related and AIDS-related events. The aim of this study was to investigate determinants potentially associated with suboptimal CD4+T cell count recovery during free ART with sustained viral suppression among an HIV-infected Yi ethnicity population in Liangshan Prefecture, an area in China with high HIV prevalence.
\end{abstract}

Methods: This retrospective study included HIV-infected Yi adults ( $\geq 18$ years and baseline CD4 $+T$ cell count less than 500 cells/ $\mathrm{LL}$ ) for whom ART supported by National Free Antiretroviral Treatment Program was initiated between January 2015 and December 2018 in Zhaojue County, Liangshan Prefecture. Virological suppression (viral load <50 copies $/ \mathrm{mL}$ ) was achieved within 12 months after ART initiation, and sustained virological suppression was maintained. Multivariate log-binomial regression analysis was used to assess determinants of suboptimal immune recovery.

Results: There were 140 female and 137 male patients in this study, with a mean age of $36.57 \pm 7.63$ years. Most of the Yi patients were infected through IDU (48.7\%) or heterosexual contact (49.8\%), and the anti-HCV antibody prevalence was high $(43.7 \%, 121 / 277)$. Of the 277 patients with a mean ART duration of $3.77 \pm 1.21$ years, complete immune recovery occurred in only $32.9 \%$. The baseline CD4 + T cell count in patients with suboptimal and intermediate immune recovery was $248.64 \pm 108.10$ and $288.59 \pm 108.86$ cells/ $/ \mathrm{L}$, respectively, which was much lower than the baseline $320.02 \pm 123.65$ cells $/ \mu \mathrm{L}$ in patients who achieved complete immune recovery $(p<0.001)$. Multivariable analysis demonstrated that low pre-ART CD4 + cell count and coinfection with HCV were associated with immune recovery of the HIV patients.

Conclusions: Our study suggests that for HIV-infected Yi patients in Liangshan Prefecture, prompt ART initiation after diagnosis of HIV infection should be applied, and curative HCV treatment should be given to patients with HCV/HIV coinfection to improve the immunological effectiveness of ART.

Trial registration None

Keywords: HIV-infected Yi ethnicity population, Sustained HIV suppression, Immune recovery

*Correspondence: anhong99999@163.com; htang6198@hotmail.com † Liyu Chen and Chang-Hai Liu contributed equally to the manuscript ${ }^{1}$ Center of Infectious Diseases, West China Hospital of Sichuan University, No.37 Guoxue Alley, Chengdu 610041, Sichuan, China

Full list of author information is available at the end of the article

\section{Strength and limitations of this study}

1. This was a retrospective study including 277 HIVinfected Yi ethnicity patients with sustained viral suppression in Liangshan Prefecture (the area with 
the highest HIV prevalence in China) to investigate potential determinants associated with suboptimal $\mathrm{CD} 4+\mathrm{T}$ cell count recovery.

2. All included patients were on NNRTI- or protease inhibitor-based ART regimens, precluding assessment of immune recovery in patients on integrasebased ART regimens.

3. HCV RNA levels were not measured in this study; therefore, patients with anti-HCV antibody positivity but low HCV RNA viral load may have been included.

\section{Introduction}

Since its first report in 1981, HIV/AIDS has remained one of the world's most serious public health challenges [1]. According to the United Nations Program on HIV/ AIDS (UNAIDS), 38.0 million people (36.2 million adults, 1.8 million children) globally lived with HIV/AIDS in 2019. Of these, 1.7 million were newly infected in 2019 (https://www.unaids.org/en). In China, the number of people living with HIV surpassed 1 million by the end of 2020 , with more than 12,000 people being newly infected (http://www.nhc.gov.cn/wjw/). Although the overall national prevalence of HIV/AIDS in China remains low, prevalence varies greatly in different regions and among different ethnic populations.

In Liangshan Yi Autonomous Prefecture, which is located in Sichuan Province, Southwest China, and is a high epidemic area, $53.84 \%$ of the population is of $\mathrm{Yi}$ ethnicity (approximately 2.86 million). Currently, all six counties (Butuo, Zhaojue, Meigu, Yuexi, Jinyang and Puge) in China with HIV/AIDS prevalence surpassing $1 \%$ are located within Liangshan Prefecture. Most of the HIV-infected individuals in Liangshan Prefecture are $\mathrm{Yi}$, and the dominant transmission routes are injection drug use (IDU) and heterosexual contact [2-5]. The high prevalence of HIV infection among the Yi population can be partly ascribed to the geographical location of Liangshan Prefecture and the culture of the Yi people. On the border with Yunnan Province, Liangshan Prefecture has long been an important channel for drug smuggling from the Golden Triangle into Sichuan Province, and the use of heroin has even been socially acceptable among the Yi people $[2,3,6]$. Poverty, casual sex, including extramarital sex and concurrent sexual partnerships, are also risk factors for the high HIV prevalence in this region.

To effectively control the HIV/AIDS epidemic in Liangshan Prefecture, China's National Free Antiretroviral Treatment Program (NFATP) [7-9] provides free antiretroviral therapy (ART) to all people living with HIV in the area. It should be noted that integrase inhibitors have not been included in NFATP, and thus most of the
ART regimens provided are non-nucleoside reverse transcriptase inhibitor (NNRTI) or protease inhibitor based. Through widespread implementation, the percentage of patients with access to ART continues to increase, enabling an growing number of HIV/AIDS patients to achieve and maintain an undetectable viral load. As undetectable equals untransmissible [10, 11], NFATP in Liangshan Prefecture has made a great contribution to the effective control of HIV transmission. Nevertheless, we observed that a considerable proportion of HIV-infected Yi patients fail to show CD4 + T cell recovery to a normal level ( $>500$ cells $/ \mu \mathrm{L}$ ), despite achieving and maintaining sustained HIV suppression, and these patients with suboptimal immune recovery are still at high risk of non-AIDS-related and AIDS-related events. To further improve ART efficacy, the aim of this study was to investigate potential determinants associated with suboptimal CD4+count recovery in HIV-infected Yi individuals who have achieved sustained viral suppression under China's NFATP in Zhaojue County, Liangshan Prefecture.

\section{Materials and methods Study design and patients}

This retrospective study included all HIV-infected $\mathrm{Yi}$ adults ( $\geq 18$ years and baseline CD4 $+\mathrm{T}$ cell count less than 500 cells $/ \mu \mathrm{L}$ ) who initiated ART supported by NFATP between January 2015 and December 2018 in Zhaojue County, Liangshan Prefecture (Fig. 1), achieving virological suppression (viral load $<50$ copies $/ \mathrm{mL}$ ) within 12 months after ART initiation and maintaining sustained virological suppression. Based on a recent study [12], immune recovery was stratified by $\mathrm{CD} 4+\mathrm{T}$ cell count measured at the most recent follow-up visit, as follows: complete immune recovery $(\mathrm{CD} 4 \geq 500$ cells $/ \mu \mathrm{L})$, intermediate immune recovery $(350 \leq \mathrm{CD} 4<500$ cells/ $\mu \mathrm{L}$ ), and suboptimal immune recovery (CD4 $<350$ cells/ $\mu \mathrm{L})$. All HIV-infected Yi patients in this study were from Zhaojue County of Liangshan Prefecture. As integrase inhibitors have not been included in NFATP, the current first-line NFATP ART regimen consists of NNRTI, either efavirenz (EFV) or nevirapine (NVP), or a protease inhibitor, either lopinavir/ritonavir (LPV/r) in combination with tenofovir disoproxil fumarate (TDF)/lamivudine (3TC) or zidovudine (AZT)/3TC.

$\mathrm{CD} 4+\mathrm{T}$ cell count was measured by flow cytometry (BD-FACSCalibur), and HIV RNA in plasma was evaluated using the Roche Cobas TaqMan HIV-1 (HPS) test every 12 months until the end of 2020. Thus, the longest follow-up time was 72 months, and the shortest followup time was 24 months. Anti-hepatitis $\mathrm{C}$ virus (HCV) antibodies and hepatitis B surface antigen ( $\mathrm{HBsAg}$ ) were measured by ELISA with HCV antibody and HBsAg test 


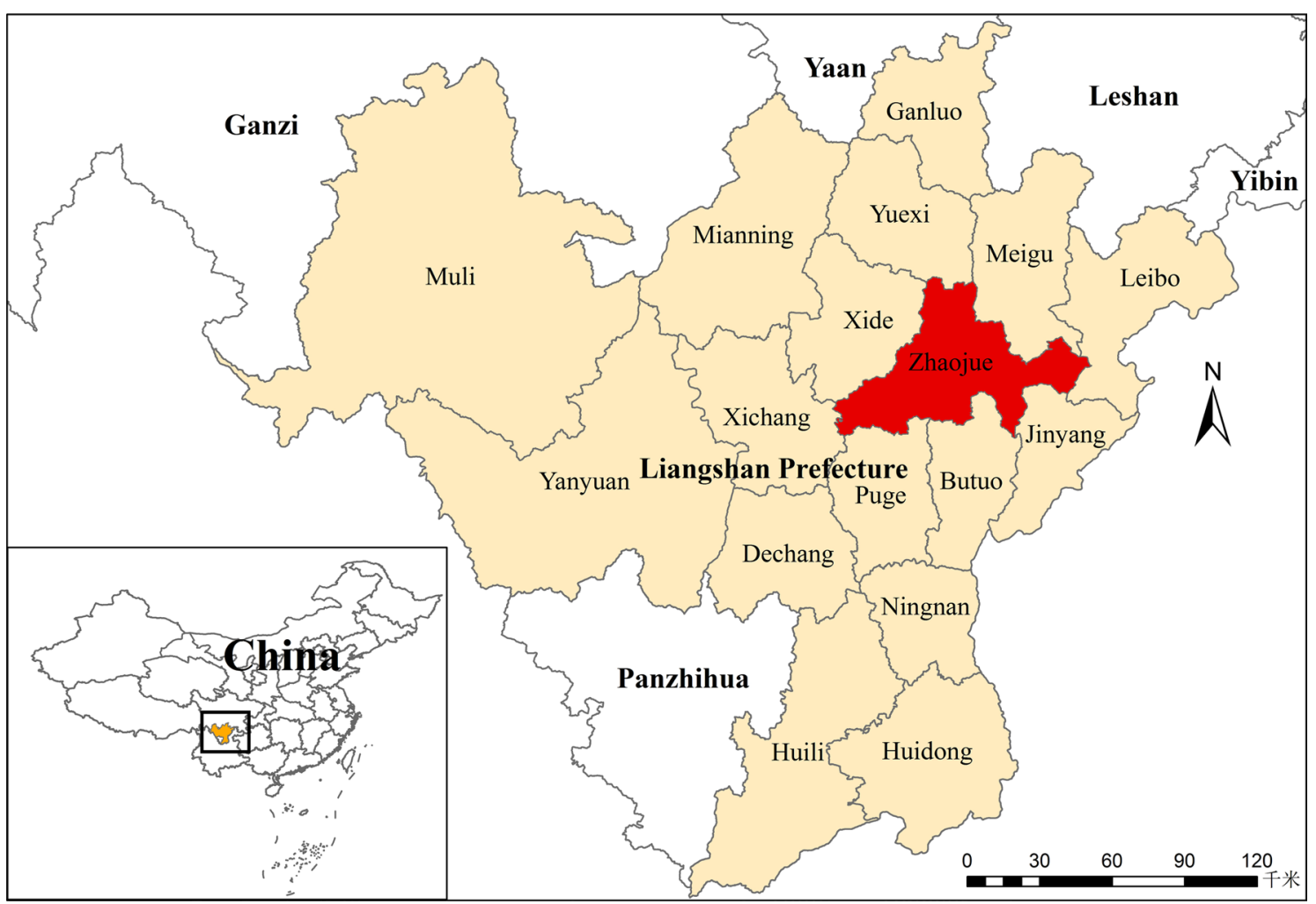

Fig. 1 Map of Liangshan Yi Autonomous Prefecture in Sichuan Province, Southwest China. All HIV-infected Yi adults included in this study were from Zhaojue County (labelled red)

kits, respectively (KHB, China). In addition, other routine follow-up tests, including haematology, urinalysis and blood liver function, were performed every 6 months; renal function for patients taking TDF was assessed every 6 months, as was the serum lipid level for patients taking $\mathrm{LPV} / \mathrm{r}$.

Anaemia was defined as haemoglobin less than $120 \mathrm{~g} / \mathrm{L}$ for men and $110 \mathrm{~g} / \mathrm{L}$ for women. Liver function test abnormalities were defined as alanine aminotransferase $($ ALT $)>40 \mathrm{U} / \mathrm{L}$, aspartate aminotransferase $(\mathrm{AST})>40$ $\mathrm{U} / \mathrm{L}$ or total bilirubin $(\mathrm{TBil})>17.1 \mu \mathrm{mol} / \mathrm{L}$. Based on a recent study, the $\mathrm{CD} 4 / \mathrm{CD} 8$ ratio was categorized into three groups: $<0.30,0.30-0.45$, and $>0.45(>0.45$ as reference) [13]. The body mass index (BMI) of the subjects was calculated by dividing the subject's weight $(\mathrm{kg})$ by the square of their height $\left(\mathrm{m}^{2}\right)$.

This study was approved by the Medical Ethics Committee of West China Hospital of Sichuan University (Annual Audit No. 450, Version 2020.5). The study was performed by following the ethical guidelines expressed in the Declaration of Helsinki and the International Conference on Harmonization Guidelines for Good Clinical Practice. Informed consent was obtained from all subjects.

\section{Statistics}

Data were extracted from NFATP Data System. Data were reported as the mean \pm standard deviation for normal continuous variables and median (interquartile range) for non-normal continuous variables; frequency was used for discrete variables. Multivariate log-binomial regression models were used to assess determinants of immune recovery, with adjusted odds ratios (aORs) and confidence intervals (CIs). Confounders or predictors for each outcome were analysed as covariates according to their biological plausibility. The nonstatistical expert-based selection method was used to determine variables to include in the multivariate regression model $[14,15]$. Variance inflation factor (VIF) and tolerance (1/VIF) values were employed to determine collinearity between factors included in multivariable analysis. All $p$ values were 2 -sided, and $p<0.05$ was considered statistically significant. Statistical analyses were performed using the statistical software SPSS (Version 24.0, IBM, Armonk, New York, USA). 


\section{Results}

Between January 2015 and December 2018, 277 HIVinfected Yi patients (with baseline CD4 $+\mathrm{T}$ cell count less than 500 cells $/ \mu \mathrm{L}$ ) who initiated ART and achieved sustained virological suppression were included in this study to investigate the incidence of suboptimal immune recovery and associated determinants (Fig. 2). There were 140 female and 137 male patients in this study, with a mean age of $36.57 \pm 7.63$ years. Most of the Yi patients were infected through IDU (48.7\%) or heterosexual contact (49.8\%).

The baseline $\mathrm{CD} 4+\mathrm{T}$ cell count in patients with suboptimal and intermediate immune recovery was $248.64 \pm 108.10$ and $288.59 \pm 108.86$ cells $/ \mu \mathrm{L}$, respectively, which was much lower than the baseline $320.02 \pm 123.65$ cells $/ \mu \mathrm{L}$ in patients who achieved complete immune recovery $(p<0.001)$. In contrast, the prevalence of anti-HCV antibody positivity in patients with suboptimal and intermediate immune recovery was much higher than that in patients with complete immune recovery $(55.0 \%$ vs. $39.5 \%$ vs. $35.2 \%, p<0.001)$ (Table 1$)$.

The prevalence of $\mathrm{HBsAg}$ positivity among the patients with suboptimal, intermediate, and complete immune recovery was $9.0 \%, 12.8 \%$, and $14.3 \%$, respectively $(p=0.507)$. Most of the included Yi patients were in WHO clinical stages I and II (269/277, 97.1\%), only 8 patients $(2.9 \%)$ were in stages III and IV. The ART regimens were mostly based on EFV $(91 \%, 251 / 277)$, followed by NVP $(5.1 \%, 14 / 277)$ and LPV/r $(3.9 \%, 11 / 277)$ in combination with TDF/3TC or AZT/3TC. Other variables, including the baseline CD4/CD8 ratio, HIV viral load, BMI, treatment duration, blood cell count, haemoglobin, and liver function, were comparable among the three groups of patients with different immune recoveries (Table 1).

During the follow-up period, the proportion of patients with CD $4+\mathrm{T}$ cell count $\geq 350$ cells $/ \mu \mathrm{L}$ increased from $31.4 \%(87 / 277)$ to $63.9 \%(177 / 277)$, and the proportion of patients with $\mathrm{CD} 4+\mathrm{T}$ cell count $\geq 200$ cells $/ \mu \mathrm{L}$ increased from $72.9 \%(202 / 277)$ to $90.3 \%$ (250/277) (Fig. 3A). However, of the 277 patients with a mean ART duration of $3.77 \pm 1.21$ years of ART, complete immune recovery occurred in only $32.9 \%$ of the included patients (Fig. 3B).

Multivariable analysis was carried out to further investigate potential determinants associated with suboptimal $\mathrm{CD} 4+$ count recovery in this population. A lower baseline CD4 + cell count was found to significantly influence achieving CD $4+$ cell recovery $>500$ cells $/ \mathrm{mL}$. Specifically, compared with patients with a pre-ART CD4+cell count $\geq 350$ cells $/ \mu \mathrm{L}$, those with a pre-ART CD $4+$ cell count in the range of $200-350$ cells/ $\mu \mathrm{L}$ (aOR 0.422, 95\% CI $0.212-0.839, p=0.014), 100-199$ cells $/ \mu \mathrm{L}$ (aOR 0.421, 95\% CI $0.871-0.895, p=0.022)$, and $<100$ cells $/ \mu \mathrm{L}(\mathrm{aOR}$ $0.478,95 \%$ CI $0.245-0.874, p=0.017$ ) had a lower chance of achieving a CD $4+$ cell count $>500$ cells $/ \mu \mathrm{L}$ (Table 2 ). However, a lower baseline CD $4+$ cell count was not found to significantly influence achieving $\mathrm{CD} 4$ cell recovery $>200$ and $>350$ cells $/ \mathrm{mL}$. Of note, the number of patients with a baseline CD $4+$ cell count $<100$ cells $/ \mathrm{mL}$ was very small $(11 / 277)$. Interestingly, coinfection with

\title{
442 patients with sustained HIV suppression under China's NFATP in Liangshan Prefecture
}

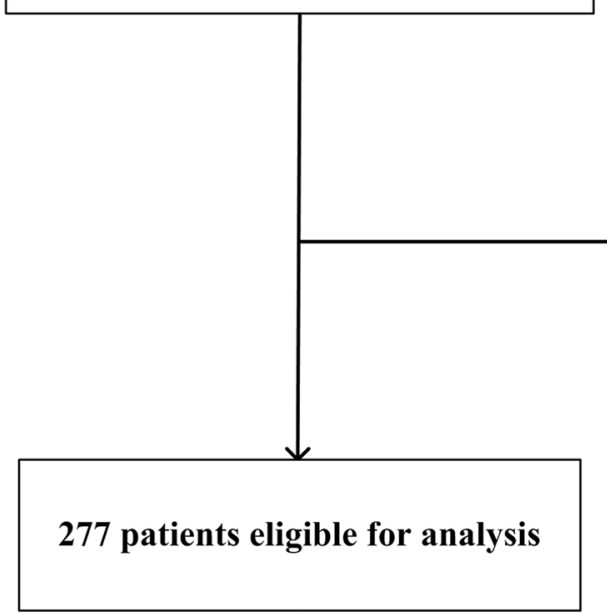

\author{
Excluded: \\ 24 patients $<18$ years \\ 12 patients with missing data \\ 8 patients with non-Yi ethnicity \\ 121 patients with baseline CD4+ T cell count $\geq 500$ cells $/ \mu \mathrm{L}$
}

Fig. 2 Flow chart of this study 
Table 1 Patients' characteristics at ART initiation

\begin{tabular}{|c|c|c|c|c|}
\hline Variables & $\begin{array}{l}\text { Suboptimal immune recovery } \\
\text { group }(n=100)\end{array}$ & $\begin{array}{l}\text { Intermediate immune } \\
\text { recovery group }(n=86)\end{array}$ & $\begin{array}{l}\text { Complete immune recovery } \\
\text { group }(n=91)\end{array}$ & $p$ value \\
\hline Sex & & & & 0.037 \\
\hline Female (\%) & $55(55.0 \%)$ & $47(54.7 \%)$ & $35(38.5 \%)$ & \\
\hline Male (\%) & $45(45.0 \%)$ & $39(45.3)$ & $56(61.5 \%)$ & \\
\hline Age (years) & $38.01 \pm 7.70$ & $36.19 \pm 8.02$ & $35.34 \pm 7.00$ & 0.462 \\
\hline 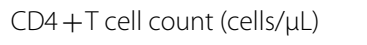 & $248.64 \pm 108.10$ & $288.59 \pm 108.86$ & $320.02 \pm 123.65$ & $<0.001$ \\
\hline CD4/CD8 ratio & $0.31 \pm 0.23$ & $0.34 \pm 0.21$ & $0.37 \pm 0.22$ & 0.179 \\
\hline HIV viral load ( $\log _{10}$ copies/mL) & $5.23 \pm 4.86$ & $5.20 \pm 4.85$ & $5.21 \pm 4.86$ & 0.527 \\
\hline $\mathrm{BMI}\left(\mathrm{kg} / \mathrm{m}^{2}\right)$ & & & & 0.061 \\
\hline$<18.5$ & 19 (19.0\%) & $5(5.8 \%)$ & $9(9.9 \%)$ & \\
\hline $18-24.5$ & $75(75.0 \%)$ & 73 (84.9\%) & $77(84.6)$ & \\
\hline$>24.5$ & $6(6.0 \%)$ & $8(9.3 \%)$ & $5(5.5 \%)$ & \\
\hline HBsAg positivity (\%) & $9(9.0 \%)$ & $11(12.8 \%)$ & $13(14.3 \%)$ & 0.507 \\
\hline Anti-HCV positivity (\%) & $55(55.0 \%)$ & $34(39.5 \%)$ & $32(35.2 \%)$ & 0.014 \\
\hline WHO stage (\%) & & & & 0.495 \\
\hline I and II & $96(96.0 \%)$ & $85(98.8 \%)$ & $88(96.7 \%)$ & \\
\hline III and IV & $4(4.0 \%)$ & $1(1.2 \%)$ & $3(3.3 \%)$ & \\
\hline ART regimens (\%) & & & & 0.423 \\
\hline$E F V+T D F+3 T C$ & $62(62.0 \%)$ & $59(68.6 \%)$ & $58(63.7 \%)$ & \\
\hline$E F V+A Z T+3 T C$ & $30(30.0 \%)$ & 18 (20.9\%) & $25(27.5 \%)$ & \\
\hline$N V P+A Z T+3 T C$ & $5(5.0 \%)$ & $2(2.3 \%)$ & $4(4.4 \%)$ & \\
\hline$N V P+T D F+3 T C$ & $1(1.0 \%)$ & $2(2.3 \%)$ & $0(0.0 \%)$ & \\
\hline $\mathrm{LPV} / \mathrm{r}+\mathrm{AZT}+3 \mathrm{TC}$ & $1(1.0 \%)$ & $4(4.7 \%)$ & $4(4.7 \%)$ & \\
\hline$L P V / r+T D F+3 T C$ & $1(1.0 \%)$ & $1(1.2 \%)$ & $0(0.0 \%)$ & \\
\hline Treatment duration (years) & $3.93 \pm 1.19$ & $3.58 \pm 1.25$ & $3.79 \pm 1.21$ & 0.155 \\
\hline Leucocyte & $6.49 \pm 3.73$ & $6.51 \pm 2.08$ & $6.50 \pm 2.10$ & 0.999 \\
\hline Platelet & $170.13 \pm 71.57$ & $178.33 \pm 62.78$ & $181.10 \pm 69.96$ & 0.513 \\
\hline Hemoglobin (g/dL) & $139.11 \pm 23.53$ & $161.20 \pm 219.73$ & $138.84 \pm 22.77$ & 0.387 \\
\hline TBil & $13.34 \pm 9.67$ & $13.85 \pm 8.22$ & $15.06 \pm 9.70$ & 0.424 \\
\hline ALT & $40.16 \pm 38.55$ & $37.76 \pm 31.76$ & $40.78 \pm 47.20$ & 0.867 \\
\hline AST & $40.38 \pm 33.47$ & $45.84 \pm 54.67$ & $40.58 \pm 35.39$ & 0.614 \\
\hline
\end{tabular}

AZT, zidovudine; 3TC, lamivudine; LPV/r, Lopinavir/ ritonavir; EFV, efavirenz; NVP, nevirapine; TDF, tenofovir disoproxil fumarate; TBil, total bilirubin; ALT, alanine aminotransferase; AST, aspartate aminotransferase

HCV was associated with a lower chance of achieving a CD $4+\mathrm{T}$ cell count $>200$ cells $/ \mu \mathrm{L}(\mathrm{aOR} 0.215,95 \% \mathrm{CI}$ $0.073-0.633, p=0.005),>350$ cells $/ \mu \mathrm{L}$ (aOR $0.45,95 \% \mathrm{CI}$ $0.245-0.834, p=0.011$ ), and $>500$ cells $/ \mu \mathrm{L}$ (aOR 0.261, $95 \%$ CI $0.095-0.716, p=0.009)$. Taken together, we demonstrate that a low pre-ART CD4+ cell count and coinfection with $\mathrm{HCV}$ are associated with immune recovery in HIV patients.

WHO clinical stage was not associated with immune recovery, which might be ascribed to the very small number of patients in stages III and IV (8/277, 2.9\%). Other variables, including age, male sex, baseline CD4/CD8 ratio, viral load, BMI, HBsAg, treatment duration, blood cell count, anaemia and liver function, were also not associated with immune recovery in this study.
To avoid the unexpected bias from different ART regimens, we excluded the 26 patients on non-EFV-based regimen and only included the 251 patients on EFVbased ART in a newly generated multivariable analysis. Similarly, low pre-ART CD4 + cell count and coinfection with $\mathrm{HCV}$ were found to be associated with suboptimal immune recovery in this population (Additional file 1: Table S1).

\section{Discussion}

With the advent of ART, HIV infection has been transformed from a death sentence to a chronic but treatable disease for most infected individuals. Nonetheless, approximately $30 \%$ of patients receiving ART fail to exhibit CD4 $+\mathrm{T}$ cell recovery to a normal level, despite 

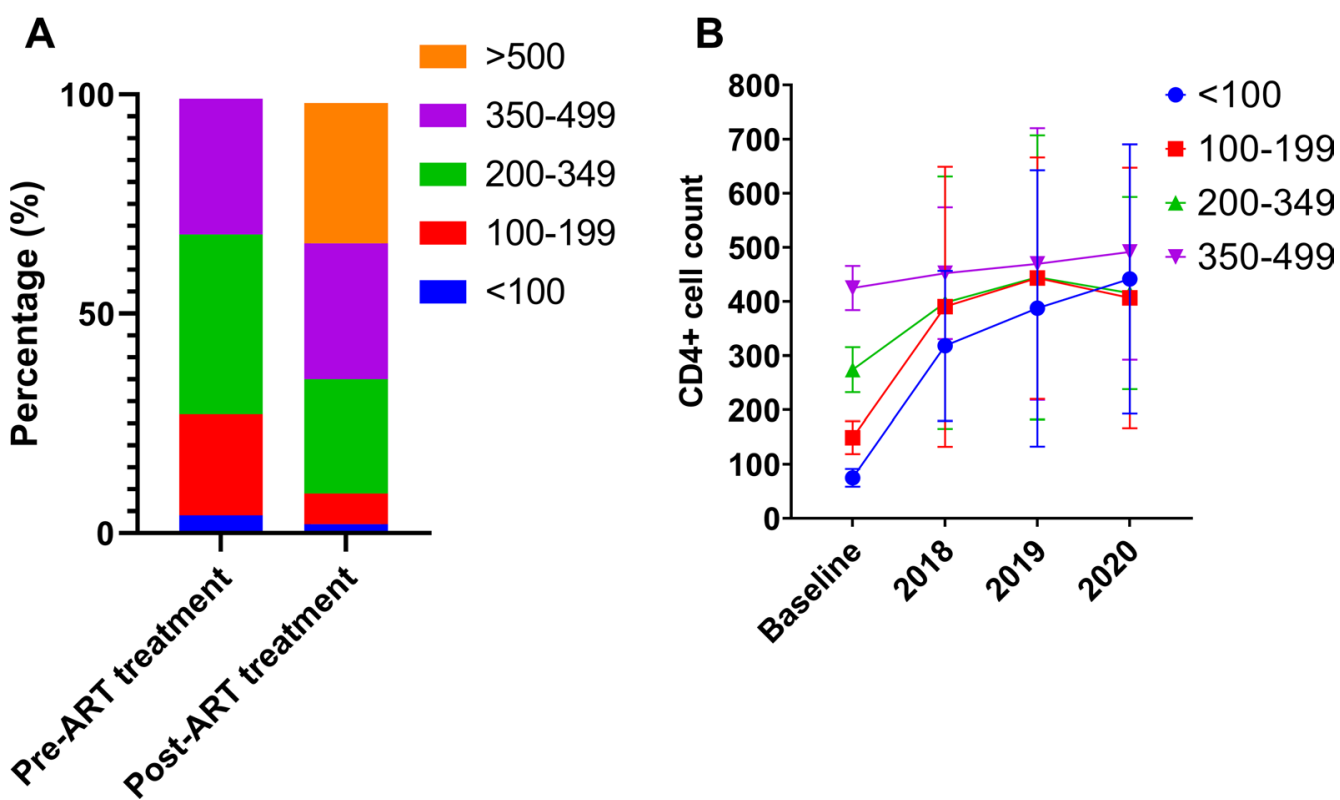

Fig. 3 The change of CD4 +T cell count with ART treatment. A Proportion of Yi patients ( $n=277)$ stratified by CD4 $+T$ cell count at baseline and the most recent follow-up visit post-ART; $\mathbf{B}$ The trends of CD4+T cell count during the follow-up

achieving sustained HIV suppression [12, 16, 17]. Persistently low CD4+T cell counts are associated with an increased risk of both AIDS-related and non-AIDSrelated morbidity and mortality [18-20]. Thus, identification of all possible risk factors involved in poor $\mathrm{CD} 4+\mathrm{T}$ cell recovery may provide clinicians guidance in choosing the most effective treatment approaches for these patients [17]. In the present study of 277 HIV-infected Chinese Yi ethnicity patients evaluated after a mean ART of $3.77 \pm 1.21$ years, we observed that a low baseline $\mathrm{CD} 4+$ cell count and HIV/HCV coinfection are associated with immune recovery in HIV patients.

To our knowledge, this is the first study to analyse risk factors potentially associated with suboptimal immune recovery in HIV-infected Yi ethnicity patients in Liangshan Prefecture, Southwest China. Through multivariable logistic regression analysis, we found a low pre-ART CD4 + cell count to be an independent risk factor for incomplete immune recovery in HIV patients, which is consistent with previous studies [12, 17, 21-23]. It has been reported that many individuals who start ART at CD $4+$ cell count $<350$ cells $/ \mu \mathrm{L}$ never achieve a normal CD $4+$ cell count $\geq 500$ cells $/ \mu \mathrm{L}$, even after up to 10 years of effective ART [22, 24]. Thus, the current international guidelines recommending that prompt or even immediate ART initiation on the day of HIV positivity diagnosis is of great importance to individuals living with HIV before they have markedly decreased $\mathrm{CD} 4+\mathrm{T}$ cell counts and progression to AIDS [25, 26].
In the present study, the prevalence of HBV/HIV coinfection was $11.9 \%$, which was comparable to the HBV/ HIV coinfection rate (13.85\%) recently reported among HIV-infected patients in Guangxi Zhuang Autonomous Region [27]. The HBV infection rate among HIV-infected individuals is much higher than that of the general population (5-6\%) in China [28]. Consistent with previous studies [28-31], our study revealed that HBV status did not influence the $\mathrm{CD} 4+\mathrm{T}$ cell response after ART initiation (Table 2). However, it needs to be emphasized that progression of chronic $\mathrm{HBV}$ infection to severe end-stage liver disease, including liver failure, cirrhosis, and hepatocellular carcinoma, occurs more rapidly in individuals with HBV/HIV coinfection than in individuals with HBV mono-infection [18, 32]. Thus, in patients with HBV/HIV coinfection, TDF or TAF in combination with FTC should be the backbone of ART because these three drugs are active against both viruses $[18,25$, 33]. The ART backbone used in this study was mostly $\mathrm{TDF} / 3 \mathrm{TC}$ (66.4\%), with the remaining $33.6 \%$ being AZT/3TC (Table 1). It is expected that the ART backbone AZT/3TC will be gradually removed from China NFATP and replaced by TDF/emtricitabine (FTC).

The prevalence of anti-HCV antibody positivity among the $277 \mathrm{HIV}$-infected Yi patients included in this study was $43.7 \%$, which may be explained by the fact that $48.7 \%$ of the patients were infected through IDU. Both $\mathrm{HCV}$ and HIV are blood-borne viruses, and the presence of HIV infection increases the transmission efficiency of 
Table 2 Determinants associated with suboptimal CD4 + count recovery among Yi patients with sustained HIV suppression on ART

\begin{tabular}{|c|c|c|c|c|c|c|}
\hline & \multicolumn{2}{|c|}{ CD4 + cell count $>200$ cells $/ \mathrm{mL}$} & \multicolumn{2}{|c|}{ CD4 + cell count $>350$ cells $/ \mathrm{mL}$} & \multicolumn{2}{|c|}{ CD4 + cell count $>500$ cells $/ \mathrm{mL}$} \\
\hline & aOR $(95 \% \mathrm{Cl})$ & $p$ value & aOR $(95 \% \mathrm{Cl})$ & $p$ value & aOR $(95 \% \mathrm{Cl})$ & $p$ value \\
\hline \multicolumn{7}{|l|}{ Age category (years) } \\
\hline $18-29$ & Reference & & Reference & & Reference & \\
\hline $30-39$ & $1.186(0.289-4.871)$ & 0.812 & $0.698(0.327-1.489)$ & 0.352 & $1.001(0.497-2.016)$ & 0.998 \\
\hline $40-49$ & $1.257(0.280-5.650)$ & 0.765 & $0.684(0.293-1.596)$ & 0.380 & $0.694(0.307-1.569)$ & 0.380 \\
\hline$\geq 50$ & 1.081 (0.080-14.645) & 0.954 & $0.462(0.119-1.793)$ & 0.265 & $0.847(0.203-3.530)$ & 0.820 \\
\hline Male sex & $2.272(0.791-6.524)$ & 0.127 & $1.258(0.681-2.321)$ & 0.464 & $1.908(1.017-3.580)$ & 0.044 \\
\hline \multicolumn{7}{|l|}{ Pre-ART CD4 + count } \\
\hline$<100$ & $0.710(0.101-4.991)$ & 0.730 & $1.140(0.285-4.559)$ & 0.853 & $0.478(0.245-0.874)$ & 0.017 \\
\hline $100-199$ & Reference & & $0.707(0.356-1.402)$ & 0.321 & $0.421(0.871-0.895)$ & 0.022 \\
\hline $200-350$ & & & Reference & & $0.422(0.212-0.839)$ & 0.014 \\
\hline $350-500$ & & & & & Reference & \\
\hline \multicolumn{7}{|l|}{ Pre-ART CD4/CD8 ratio } \\
\hline$>0.45$ & Reference & & Reference & & Reference & \\
\hline $0.30-0.45$ & $0.062(0.006-0.603)$ & 0.017 & $0.824(0.347-1.959)$ & 0.661 & $0.635(0.289-1.398)$ & 0.260 \\
\hline$<0.30$ & $0.164(0.017-1.624)$ & 0.122 & $0.704(0.306-1.617)$ & 0.408 & $0.655(0.302-1.422)$ & 0.284 \\
\hline \multicolumn{7}{|l|}{ HIV viral load (copies/ml) } \\
\hline$<100000$ & Reference & & Reference & & Reference & \\
\hline$>100000$ & $0.746(0.229-2.434)$ & 0.628 & $0.604(0.295-1.236)$ & 0.168 & $0.935(0.473-1.848)$ & 0.846 \\
\hline \multicolumn{7}{|l|}{ BMI $\left(\mathrm{kg} / \mathrm{m}^{2}\right)$} \\
\hline$<18.5$ & $0.844(0.242-2.943)$ & 0.790 & $0.399(0.173-0.920)$ & 0.031 & $0.749(0.300-1.871)$ & 0.536 \\
\hline $18.5-24$ & Reference & & Reference & & Reference & \\
\hline$>28$ & $0.814(0.263-2.367)$ & 0.998 & $1.359(0.448-4.123)$ & 0.588 & $0.822(0.257-2.625)$ & 0.740 \\
\hline HBsAg positive & $9.098(0.964-85.897)$ & 0.054 & $1.445(0.584-3.577)$ & 0.426 & $1.299(0.569-2.965)$ & 0.534 \\
\hline Anti-HCV positive & $0.215(0.073-0.633)$ & 0.005 & $0.453(0.245-0.834)$ & 0.011 & $0.261(0.095-0.716)$ & 0.009 \\
\hline \multicolumn{7}{|l|}{ WHO clinical stage } \\
\hline | and || & Reference & & Reference & & Reference & \\
\hline III and IV & $0.104(0.010-1.045)$ & 0.054 & $0.541(0.108-2.703)$ & 0.454 & $1.197(0.227-6.303)$ & 0.832 \\
\hline Treatment duration $>3$ years & $0.555(0.192-1.602)$ & 0.277 & $0.552(0.304-1.001)$ & 0.050 & $0.900(0.502-1.614)$ & 0.725 \\
\hline Leucocyte $<4$ or $>10 \times 10^{9} / \mathrm{L}$ & $1.408(0.318-6.243)$ & 0.653 & $1.295(0.552-3.034)$ & 0.552 & $1.451(0.621-3.389)$ & 0.389 \\
\hline Platelet $<100 \times 10^{9} / \mathrm{L}$ & $2.125(0.433-10.432)$ & 0.353 & $0.589(0.249-1.393)$ & 0.228 & $0.892(0.347-2.296)$ & 0.813 \\
\hline Anemia & $0.445(0.104-1.906)$ & 0.275 & $0.836(0.341-2.049)$ & 0.695 & $0.856(0.327-2.243)$ & 0.752 \\
\hline TBil > $17.1 \mu \mathrm{mol} / \mathrm{L}$ & $0.979(0.333-2.883)$ & 0.970 & $1.663(0.841-3.289)$ & 0.144 & $1.824(0.945-3.520)$ & 0.073 \\
\hline $\mathrm{ALT}>40 \mathrm{U} / \mathrm{L}$ & $0.914(0.255-3.273)$ & 0.890 & $1.159(0.525-2.560)$ & 0.715 & $1.136(0.512-2.524)$ & 0.753 \\
\hline $\mathrm{AST}>40 \mathrm{U} / \mathrm{L}$ & $0.617(0.179-2.127)$ & 0.444 & $1.225(0.570-2.629)$ & 0.603 & $1.084(0.503-2.337)$ & 0.837 \\
\hline
\end{tabular}

HCV [34]. It has been reported that HCV prevalence in HIV-infected individuals is much higher than that in HIV-negative individuals, especially in people who inject drugs [34]. HIV coinfection accelerates $\mathrm{HCV}$ progression, as patients with HCV/HIV coinfection have a 2.92fold greater risk of experiencing progression to severe liver diseases than do patients with HCV mono-infection [35]. However, the effect of $\mathrm{HCV}$ infection on $\mathrm{CD} 4+\mathrm{T}$ cell recovery after efficient ART remains controversial. Some studies reported that the $\mathrm{CD} 4+\mathrm{T}$ cell recovery was comparable between HCV/HIV coinfected patients and HIV-mono-infected patients on efficient ART [36] or that clearance of HCV replication did not influence immune recovery [37]. In contrast, several studies have found that despite sustained HIV suppression due to efficient ART, HCV/HIV coinfected patients have a lower probability of achieving optimal immune recovery than patients with HIV mono-infection [38-42]. Our present study also revealed a negative correlation between $\mathrm{HCV}$ infection and optimal CD4 $+\mathrm{T}$ cell recovery (Table 2), suggesting that all patients with HCV/HIV coinfection should be evaluated for curative HCV treatment [18]. With the advent of direct-acting antiviral (DAA) therapies, HIV/HCV coinfection is no longer difficult to treat 
[43]. Of note, when concurrent treatments for both HIV and $\mathrm{HCV}$ are indicated, careful consideration needs to be taken regarding drug-drug interactions between ART drugs and HCV DAAs [44]. In the present study, more than $95 \%$ of the ART regimens were EFV- and NVPbased (Table 1). The DAA regimen sofosbuvir/ledipasvir is recommended for $\mathrm{HCV}$ eradication, whereas the DAA regimens sofosbuvir/velpatasvir, elbasvir/grazoprevir, and glecaprevir/pibrentasvir are contraindicated. As velpatasvir, elbasvir, grazoprevir, and glecaprevir are substrates of cytochrome P450 3A (CYP3A), their serum concentrations become reduced when co-administrated with EFV and NVP (CYP3A inducers) [18, 45].

Our study has limitations. First, all included patients were on NNRTI-based or protease inhibitor-based ART regimens, precluding assessment of immune recovery in patients on integrase-based ART regimens. Second, HCV RNA levels were not measured in this study; therefore, patients with anti-HCV antibody positivity but a low HCV RNA viral load may have been included. Third, there was a lack of data on smoking behaviour, which has been reported to play a role in suboptimal immune recovery $[46,47]$. Fourth, the number of included Yi patients on efficient ART was relatively small, which may limit the identification of other determinants associated with suboptimal $\mathrm{CD} 4+\mathrm{T}$ cell count recovery. Future studies are needed to include more Yi patients from Liangshan Prefecture to investigate more factors (e.g., cigarette smoking and alcohol consumption) likely to influence the immune recovery of HIV-infected patients on efficient ART $[17,21,48,49]$.

In summary, we demonstrate that a low pre-ART CD4 + cell count and HCV infection are associated with suboptimal CD4+ count recovery among HIV-infected Yi individuals on efficient ART in Liangshan Prefecture. Our study supports prompt ART initiation after HIV diagnosis and $\mathrm{HCV}$ eradication treatment in $\mathrm{HCV} / \mathrm{HIV}$ coinfected patients by appropriate DAA regimens (compatible with HIV ART antiretrovirals), not only for $\mathrm{HCV}$ cure per se but also for improving the immunological effectiveness of ART.

\footnotetext{
Abbreviations

UNAIDS: United Nations Program on HIV/AIDS; IDU: Injection drug use; ART: Anti-retroviral therapy; NFATP: National Free Antiretroviral Treatment Program; NNRTI: Non-nucleoside reverse transcriptase inhibitor; EFV: Efavirenz; NVP: Nevirapine; LPV/r: Lopinavir/ritonavir; TDF: Tenofovir disoproxil fumarate; $3 T C$ : Lamivudine; AZT: Zidovudine; HCV: Hepatitis C virus; HBV: Hepatitis B virus; TBil: Total bilirubin; ALT: Alanine aminotransferase; AST: Aspartate aminotransferase;
}

aOR: Adjusted odds ratio; Cl: Confidence interval; VIF: Variance inflation factor; CYP3A: Cytochrome P450-3A.

\section{Supplementary Information}

The online version contains supplementary material available at https://doi. org/10.1186/s12879-022-07113-y.

Additional file 1: Table S1. Determinants associated with suboptimal CD4 + count recovery among 251 Yi patients with sustained HIV suppression on EFV-based ART.

Additional file 2. Checklist for the appropriate reporting statement: STROBE.

\section{Acknowledgements}

None.

\section{Authors' contributions}

Guarantor of the article: HT, HL. Study design: HT, HL, LYC. Drafting the manuscript: LYC, HL, HT. Statistical analyses and interpretation: $\mathrm{CHL}, \mathrm{HL}$. Data acquisition: $L Y C, C H L, S K, L Y D, F H M, C M L, L B, H L, H T$. Critical revision of the manuscript: HT, LYC, CHL. All authors read and approved the final manuscript.

\section{Funding}

This research was funded by the 1.3.5 project for disciplines of excellence, West China Hospital, Sichuan University (No. ZYGD20009).

\section{Availability of data and materials}

All data generated or analysed during this study are included in this published article and its additional files.

Checklist for the appropriate reporting statement: STROBE (in Additional file 2).

\section{Declarations}

\section{Ethics approval and consent to participate}

This study was approved by the Medical Ethics Committee of West China Hospital of Sichuan University (No. 450, Version 2020.5) (in related files). The study was performed by following the ethical guidelines expressed in the Declaration of Helsinki and the International Conference on Harmonization Guidelines for Good Clinical Practice. Informed consent was obtained from all subjects.

\section{Consent for publication}

The present study was a retrospective study design and did not contain specific personal medical information (video or image) about an identifiable living individual.

\section{Competing interests}

The authors declare that they have no competing interests.

\section{Author details}

${ }^{1}$ Center of Infectious Diseases, West China Hospital of Sichuan University, No.37 Guoxue Alley, Chengdu 610041, Sichuan, China. ${ }^{2}$ Division of Infectious Diseases, State Key Laboratory of Biotherapy and Center of Infectious Diseases, West China Hospital, Sichuan University, Chengdu, China. ${ }^{3}$ Center of Antiretroviral Treatment, People's Hospital of Zhaojue County 616150, Liangshan, Yi Autonomous Prefecture, China.

Received: 9 June 2021 Accepted: 28 January 2022

Published online: 08 February 2022 


\section{References}

1. Gottlieb MS, Schroff R, Schanker HM, Weisman JD, Fan PT, Wolf RA, et al. Pneumocystis carinii pneumonia and mucosal candidiasis in previously healthy homosexual men: evidence of a new acquired cellular immunodeficiency. N Engl J Med. 1981;305(24):1425-31.

2. Wang H, Chen AC, Wan S, Chen H. Status and associated factors of selfmanagement in people living with HIV/AIDS in Liangshan area, China: a cross-sectional study. Patient Prefer Adherence. 2019;13:863-70.

3. Yang Y, Latkin C, Luan R, Yang C. Reality and feasibility for pharmacy-delivered services for people who inject drugs in Xichang, China: comparisons between pharmacy staff and people who inject drugs. Int J Drug Policy. 2016:27:113-20.

4. Zhang G, Gong Y, Wang Q, Deng L, Zhang S, Liao Q, et al. Outcomes and factors associated with survival of patients with HIV/AIDS initiating antiretroviral treatment in Liangshan Prefecture, southwest of China: A retrospective cohort study from 2005 to 2013. Medicine. 2016;95(27):e3969.

5. Yang S, Zhai W, Pei R, Jike C, Nan L, Yu G, et al. Factors associated with HIV infection among Yi minority residents in Liangshan Prefecture, Sichuan Province: A path analysis. Medicine. 2018;97(14):e0250.

6. Yang S, Yang C, Liao Q, Zhai W, Yu G, Xiao L, et al. Analysis of HIV prevalence among pregnant women in Liangshan Prefecture, China, from 2009 to 2015. PLoS ONE. 2017;12(9):e0183418.

7. Zhang F, Dou Z, Ma Y, Zhao Y, Liu Z, Bulterys M, et al. Five-year outcomes of the China National Free Antiretroviral Treatment Program. Ann Intern Med. 2009;151(4):241-512

8. Cao W, Hsieh E, Li T. Optimizing Treatment for Adults with HIV/AIDS in China: Successes over Two Decades and Remaining Challenges. Curr HIV/ AIDS Rep. 2020;17(1):26-34.

9. Zhang F, Zhu H, Wu Y, Dou Z, Zhang Y, Kleinman N, et al. HIV, hepatitis B virus, and hepatitis $C$ virus co-infection in patients in the China National Free Antiretroviral Treatment Program, 2010-12: a retrospective observational cohort study. Lancet Infect Dis. 2014;14(11):1065-72.

10. Eisinger RW, Dieffenbach CW, Fauci AS. HIV viral load and transmissibility of HIV infection: undetectable equals untransmittable. JAMA 2019;321(5):451-2.

11. Thomford NE, Mhandire D, Dandara C, Kyei GB. Promoting Undetectable Equals Untransmittable in Sub-Saharan Africa: implication for clinical practice and ART Adherence. Int J Environ Res Public Health. 2020;17:17.

12. Handoko R, Colby DJ, Kroon E, Sacdalan C, de Souza M, Pinyakorn S, et al. Determinants of suboptimal CD4(+)T cell recovery after antiretroviral therapy initiation in a prospective cohort of acute HIV-1 infection. J Int AIDS Soc. 2020;23(9):e25585.

13. Mussini C, Lorenzini P, Cozzi-Lepri A, Lapadula G, Marchetti G, Nicastri $E$, et al. CD4/CD8 ratio normalisation and non-AIDS-related events in individuals with HIV who achieve viral load suppression with antiretroviral therapy: an observational cohort study. The lancet HIV. 2015;2(3):e98-106.

14. Stavseth MR, Clausen T, Røislien J. The clinical consequences of variable selection in multiple regression models: a case study of the Norwegian Opioid Maintenance Treatment program. Am J Drug Alcohol Abuse 2020;46(1):13-21.

15. Moons KGM, Wolff RF, Riley RD, Whiting PF, Westwood M, Collins GS, et al. PROBAST: A tool to assess risk of bias and applicability of prediction model studies: explanation and elaboration. Ann Intern Med. 2019;170(1):W1-w33.

16. Battegay M, Nüesch R, Hirschel B, Kaufmann GR. Immunological recovery and antiretroviral therapy in HIV-1 infection. Lancet Infect Dis. 2006;6(5):280-7.

17. Gazzola L, Tincati C, Bellistrì GM, Monforte A, Marchetti G. The absence of CD4+ T cell count recovery despite receipt of virologically suppressive highly active antiretroviral therapy: clinical risk, immunological gaps, and therapeutic options. Clin Infect Dis. 2009:48(3):328-37.

18. Al-Mrabeh A, Hollingsworth KG, Steven S, Taylor R. Morphology of the pancreas in type 2 diabetes: effect of weight loss with or without normalisation of insulin secretory capacity. Diabetologia. 2016;59(8):1753-9.

19. Baker JV, Peng G, Rapkin J, Krason D, Reilly C, Cavert WP, et al. Poor initial CD4+ recovery with antiretroviral therapy prolongs immune depletion and increases risk for AIDS and non-AIDS diseases. J Acquir Immune Defic Syndr. 2008;48(5):541-6.
20. Baker JV, Peng G, Rapkin J, Abrams DI, Silverberg MJ, MacArthur RD, et al. CD4+ count and risk of non-AIDS diseases following initial treatment for HIV infection. AIDS (London, England). 2008;22(7):841-8.

21. Kroeze S, Ondoa P, Kityo CM, Siwale M, Akanmu S, Wellington M, et al. Suboptimal immune recovery during antiretroviral therapy with sustained HIV suppression in sub-Saharan Africa. AIDS (London, England) 2018;32(8):1043-51.

22. Moore RD, Keruly JC. CD4+ cell count 6 years after commencement of highly active antiretroviral therapy in persons with sustained virologic suppression. Clin Infect Dis. 2007;44(3):441-6.

23. Han WM, Ubolyam S, Apornpong T, Kerr SJ, Hansasuta P, Gatechompol $S$, et al. Characteristics of suboptimal immune response after initiating antiretroviral therapy among people living with HIV with a pretreatment CD4 T cell count $<200$ cells $/ \mathrm{mm}$ (3) in Thailand. J Virus Erad. 2020;6(3):100005

24. Palella FJ Jr, Armon C, Chmiel JS, Brooks JT, Hart R, Lichtenstein K, et al. CD4 cell count at initiation of ART, long-term likelihood of achieving CD4 $>750$ cells/mm3 and mortality risk. J Antimicrob Chemother. 2016;71(9):2654-62.

25. AIDS and Hepatitis C Professional Group SolG, Chinese Medical Association; Chinese Center for Disease Control and Prevention. Chinese guidelines for diagnosis and treatment of HIV/AIDS. Zhonghua. 2018;57(12):867-84

26. Le T, Wright EJ, Smith DM, He W, Catano G, Okulicz JF, et al. Enhanced CD4+ T-cell recovery with earlier HIV-1 antiretroviral therapy. N Engl J Med. 2013;368(3):218-30.

27. Feng D, Yao T, Cheng YP, Pan MH, Li CX, Wang J, et al. Prevalence and related factors of HIV/HBV coinfection among HIV/AIDS patients. Zhonghua. 2017:38(12):1624-8.

28. Liu J, Liang W, Jing W, Liu M. Countdown to 2030: eliminating hepatitis B disease, China. Bull World Health Organ. 2019:97(3):230-8.

29. Hoffmann CJ, Seaberg EC, Young S, Witt MD, D'Acunto K, Phair J, et al. Hepatitis B and long-term HIV outcomes in coinfected HAART recipients. AIDS (London, England). 2009;23(14):1881-9.

30. Hoffmann CJ, Charalambous S, Martin DJ, Innes C, Churchyard GJ, Chaisson $\mathrm{RE}$, et al. Hepatitis $\mathrm{B}$ virus infection and response to antiretroviral therapy (ART) in a South African ART program. Clin Infect Dis. 2008:47(11):1479-85.

31. Konopnicki D, Mocroft A, de Wit S, Antunes F, Ledergerber B, Katlama $C$, et al. Hepatitis B and HIV: prevalence, AIDS progression, response to highly active antiretroviral therapy and increased mortality in the EuroSIDA cohort. AIDS (London, England). 2005;19(6):593-601.

32. Thio CL, Seaberg EC, Skolasky R Jr, Phair J, Visscher B, Muñoz A, et al. HIV-1, hepatitis B virus, and risk of liver-related mortality in the Multicenter Cohort Study (MACS). Lancet (London, England). 2002;360(9349):1921-6.

33. Kosi L, Reiberger T, Payer BA, Grabmeier-Pfistershammer K, StrassI R, Rieger A, et al. Five-year on-treatment efficacy of lamivudine-, tenofovir- and tenofovir + emtricitabine-based HAART in HBV-HIV-coinfected patients. J Viral Hepat. 2012;19(11):801-10.

34. Platt L, Easterbrook P, Gower E, McDonald B, Sabin K, McGowan C, et al. Prevalence and burden of HCV co-infection in people living with HIV: a global systematic review and meta-analysis. Lancet Infect Dis. 2016:16(7):797-808

35. Graham CS, Baden LR, Yu E, Mrus JM, Carnie J, Heeren T, et al. Influence of human immunodeficiency virus infection on the course of hepatitis $C$ virus infection: a meta-analysis. Clin Infect Dis. 2001;33(4):562-9.

36. Kaufmann GR, Perrin L, Pantaleo G, Opravil M, Furrer $H$, Telenti A, et al. CD4 T-lymphocyte recovery in individuals with advanced HIV-1 infection receiving potent antiretroviral therapy for 4 years: the Swiss HIV Cohort Study. Arch Intern Med. 2003;163(18):2187-95.

37. Milazzo L, Foschi A, Mazzali C, Viola A, Ridolfo A, Galli M, et al. Short communication: impact of hepatitis C viral clearance on CD4+ T-lymphocyte course in HIV/HCV-coinfected patients treated with pegylated interferon plus ribavirin. AIDS Res Hum Retroviruses. 2012:28(9):989-93.

38. Reiberger T, Payer BA, Kosi L, Heil PM, Rieger A, Peck-Radosavljevic M. Concomitant highly active antiretroviral therapy leads to smaller decline and faster recovery of CD4+ cell counts during and after pegylated interferon plus ribavirin therapy in HIV-hepatitis C virus coinfected patients. J Infect Dis. 2011;203(12):1802-6.

39. Motta D, Brianese N, Focà E, Nasta P, Maggiolo F, Fabbiani M, et al. Virological effectiveness and CD4+ T-cell increase over early and late courses 
in HIV infected patients on antiretroviral therapy: focus on HCV and anchor class received. AIDS Res Ther. 2012;9(1):18.

40. Potter M, Odueyungbo A, Yang H, Saeed S, Klein MB. Impact of hepatitis C viral replication on CD4+ T-lymphocyte progression in HIV-HCV coinfection before and after antiretroviral therapy. AIDS (London, England). 2010;24(12):1857-65.

41. Greub G, Ledergerber B, Battegay M, Grob P, Perrin L, Furrer H, et al. Clinical progression, survival, and immune recovery during antiretroviral therapy in patients with HIV-1 and hepatitis C virus coinfection: the Swiss HIV Cohort Study. Lancet (London, England). 2000;356(9244):1800-5.

42. Braitstein P, Zala C, Yip B, Brinkhof MW, Moore D, Hogg RS, et al. Immunologic response to antiretroviral therapy in hepatitis $C$ virus-coinfected adults in a population-based HIV/AIDS treatment program. J Infect Dis. 2006;193(2):259-68.

43. Sikavi C, Chen PH, Lee AD, Saab EG, Choi G, Saab S. Hepatitis C and human immunodeficiency virus coinfection in the era of direct-acting antiviral agents: No longer a difficult-to-treat population. Hepatology (Baltimore, MD). 2018;67(3):847-57.

44. Rockstroh JK. Optimal therapy of HIV/HCV co-infected patients with direct acting antivirals. Liver Int. 2015;35(Suppl 1):51-5.

45. Hernaez R, Solà E, Moreau R, Ginès P. Acute-on-chronic liver failure: an update. Gut. 2017:66(3):541-53.

46. Winhusen T, Feaster DJ, Duan R, Brown JL, Daar ES, Mandler R, et al. Baseline cigarette smoking status as a predictor of virologic suppression and CD4 cell count during one-year follow-up in substance users with uncontrolled HIV Infection. AIDS Behav. 2018;22(6):2026-32.

47. Feldman JG, Minkoff H, Schneider MF, Gange SJ, Cohen M, Watts DH, et al. Association of cigarette smoking with HIV prognosis among women in the HAART era: a report from the women's interagency HIV study. Am J Public Health. 2006;96(6):1060-5.

48. Serrano-Villar S, Martínez-Sanz J, Ron R, Talavera-Rodríguez A, FernándezFelix BM, Herrera S, et al. Effects of first-line antiretroviral therapy on the CD4/CD8 ratio and CD8 cell counts in CoRIS: a prospective multicentre cohort study. The lancet HIV. 2020;7(8):e565-73.

49. Malbergier A, Amaral RA, Cardoso LD. Alcohol dependence and CD4 cell count: is there a relationship? AIDS Care. 2015;27(1):54-8.

\section{Publisher's Note}

Springer Nature remains neutral with regard to jurisdictional claims in published maps and institutional affiliations.

Ready to submit your research? Choose BMC and benefit from:

- fast, convenient online submission

- thorough peer review by experienced researchers in your field

- rapid publication on acceptance

- support for research data, including large and complex data types

- gold Open Access which fosters wider collaboration and increased citations

- maximum visibility for your research: over $100 \mathrm{M}$ website views per year

At BMC, research is always in progress.

Learn more biomedcentral.com/submissions 